\title{
Bullying: peer-to-peer maltreatment with severe consequences for child and adolescent mental health
}

\author{
Michael Kaess ${ }^{1,2}$
}

Published online: 12 July 2018

○) Springer-Verlag GmbH Germany, part of Springer Nature 2018

In the past decades, research on the development of mental disorders has increasingly set a strong focus on the identification and investigation of environmental risk factors. Ideally, such risk factors can be used as potential targets for prevention. Among the most important factors that may either positively or negatively influence an individual's environment are interpersonal experiences and relationships.

Without a doubt, childhood maltreatment (mostly comprised of childhood experiences of abuse and neglect) is among the most important environmental risk factor for the development of mental-health problems including internalizing and externalizing psychopathology, posttraumatic stress disorder, and personality disorders [1] as well as suicidal behavior [2]. In addition, other adverse childhood experiences such as parental loss or parental maladjustment have been identified as risk factors that contribute in an additive manner to the development of psychopathology [3]. Common to all the risk factors mentioned above is that they commonly refer to adult-child relationships, and focus less on the relationship among peers.

Peer relationships, however, play an important role in children's and adolescents' lives, and the importance of peer relationships steadily rises with increasing age. Similar to adult-child relationships, the quality of peer relationships may heavily impact mental health. This is particularly true for severely abusive or neglectful peer relationships that can also be labeled as "bullying".

Bullying is defined as repeated negative actions over a prolonged period, performed by a single individual or group and carried out in direct or indirect form. Key criteria of

Michael Kaess

Michael.Kaess@upd.ch

1 University Hospital of Child and Adolescent Psychiatry and Psychotherapy, University of Bern, Bern, Switzerland

2 Clinic of Child and Adolescent Psychiatry, Center for Psychosocial Medicine, University Hospital Heidelberg, Heidelberg, Germany bullying are the harmful intent of the perpetrator as well as an existing imbalance of power between victim and perpetrator [4]. Thus, bullying is a man-made, intentional aggression, which is consistent with the defining features of maltreatment or abuse.

The large-scale study "Health Behaviour in School-Aged Children", which collected data from more than 200,000 adolescents in 40 European countries, reported bullying rates ranging from 7 to $40 \%$ dependent on the country. Overall, $26.9 \%$ of the participants were affected by bullying, as either victims or perpetrators, or both (so-called bully/victims). The overall number of individuals who had experienced bullying victimization was $16.2 \%$ [5]. Most bullying happens in schools; however, cyberbullying has received increased public and academic attention due to its novelty and potential additive impact and harm. Recent research, however, concluded that cyberbullying creates few new victims, but is mainly a new tool to harm victims already bullied by traditional means [6]. Nonetheless, cyberbullying may extend the reach of bullying beyond the school gate and may be even less visible and controllable for adults who might be able to intervene. Another social space that has long been neglected as a place for bullying is the family where bullying often occurs among siblings (so-called sibling bullying) [7].

Consistent with other experiences of maltreatment, the distress and suffering caused by bullying is enormous. Bullying shows strong associations with both non-suicidal selfinjury $[8,9]$ and suicidal behavior [8, 10]. For example, prospective studies revealed elevated odds for emotional disorders [11] and personality disorders [12] among those who were bullied. Overall, previous victims of school bullying were found to be at higher risk for poor general health and lower educational achievement [13, 14].

At the 17th International Congress of European Society of Child and Adolescent Psychiatry (ESCAP) 2017 in Geneva/Switzerland, Professor Dieter Wolke gave an impressive lecture entitled "Peers and siblings matter for mental health: long-term consequences of bullying." In this 
lecture, Professor Wolke highlighted that children will have spent much more time with their peers than their parents by the time they reach 18 years of age. Interestingly, he presented data suggesting that the adverse effects of bullying may exceed those of childhood maltreatment. Two studies from his group clearly showed that children who were bullied only were more likely to have mental-health problems than children who were maltreated only [15].

Given that bullying is a highly prevalent phenomenon, which has long-lasting negative consequences that are comparable to those of childhood maltreatment, it is surprising that bullying has not yet been equally recognized as both a research area of particular interest and a major public health concern. In the following, I will try to highlight a few selected areas related to bullying that should be targeted in the field of child and adolescent psychiatry and beyond:

First, research on childhood maltreatment has recently involved a concerted effort to identify potential mechanisms by which maltreatment may increase risk for various mental disorders, including genetic, biological, and psychosocial factors that either moderate or mediate the relationship between maltreatment and risk for psychopathology [1]. More research on understanding the potential mechanisms and pathways that lead from bullying to different types of mental illness is urgently needed, and may finally help to improve treatment and prevention for those who have been bullied.

Second, given that bullying can be regarded as a type of maltreatment, it should also be considered a potential traumatic experience. Indeed, some research suggests that bullying may lead to posttraumatic stress disorder (PTSD): two studies in children and adolescents found approximately one-third of bully victims presented with clinically relevant symptoms of PTSD [16, 17]. Since evidence-based treatments are available for trauma-related disorders as a result of childhood maltreatment [18], such treatment approaches may also be adapted and tested for victims of bullying.

Third, the relatively new phenomena of cyberbullying and sibling bullying, which have only briefly been mentioned above, need further studies to evaluate their incidence, consequences, and additional impact. In addition, prevention and intervention efforts need to include these types of bullying, as they cannot be covered by the school-based programs available.

Fourth, while there is evidence for the effectiveness of bullying prevention programs [19], randomized-controlled trials are still urgently needed, and further developments of existing interventions are critical given that the programs available reduce bullying by only $20-25 \%$, which is unsatisfactory. In addition to universal bullying prevention, indicated prevention might be considered for individuals who are at particular risk of being bullied. For example, there is clear evidence that individuals with attention deficit/ hyperactivity disorder have higher rates of peer victimization [20].

Fifth, since costs to society and potential cost effectiveness of interventions are nowadays a very important factor influencing decisions on resource allocation, we are in need of more research and data that can answer the question: What are the costs of bullying to society and how much can we potentially save by preventing a case of bullying? Again, such data are available for childhood maltreatment [21].

Last, the current evidence for the incidence and consequences of bullying call for large-scale public health initiatives that may include awareness campaigns for the general public and for schools in particular, dissemination of evidence-based bullying prevention programs, the development of guidelines and specific interventions for preventing and treating the consequences of bullying, and additional research funding for innovative research around the phenomenon of bullying (comparable to the many calls that have been implemented for the field of childhood maltreatment in the past years).

To conclude, bullying is peer-to-peer maltreatment. Accordingly, it has serious consequences for the development of mental-health problems and deserves a high level of attention and efforts in the field of child and adolescent psychiatry but also far beyond.

\section{References}

1. Jaffee SR (2017) Child maltreatment and risk for psychopathology in childhood and adulthood. Annu Rev Clin Psychol 13:525-551. https://doi.org/10.1146/annurev-clinpsy-032816-045005

2. Zatti C, Rosa V, Barros A et al (2017) Childhood trauma and suicide attempt: a meta-analysis of longitudinal studies from the last decade. Psychiatry Res 256:353-358. https://doi.org/10.1016/j. psychres.2017.06.082

3. Green JG, McLaughlin KA, Berglund PA et al (2010) Childhood adversities and adult psychiatric disorders in the national comorbidity survey replication I: associations with first onset of DSM-IV disorders. Arch Gen Psychiatry 67:113-123. https://doi. org/10.1001/archgenpsychiatry.2009.186

4. Olweus D (1994) Annotation: bullying at school: basic facts and effects of a school based intervention program. Child Psychol Psychiatry Allied Discip 35:1171-1190. https://doi. org/10.1111/j.1469-7610.1994.tb01229.x

5. Craig W, Harel-Fisch Y, Fogel-Grinvald H et al (2009) A crossnational profile of bullying and victimization among adolescents in 40 countries. Int J Public Health 54(Suppl 2):216-224. https:// doi.org/10.1007/s00038-009-5413-9

6. Wolke D, Lee K, Guy A (2017) Cyberbullying: a storm in a teacup? Eur Child Adolesc Psychiatry 26:899-908. https://doi. org/10.1007/s00787-017-0954-6

7. Wolke D, Tippett N, Dantchev S (2015) Bullying in the family: sibling bullying. Lancet Psychiatry 2:917-929. https://doi. org/10.1016/S2215-0366(15)00262-X

8. Jantzer V, Haffner J, Parzer P et al (2015) Does parental monitoring moderate the relationship between bullying and adolescent 
nonsuicidal self-injury and suicidal behavior? A community-based self-report study of adolescents in Germany. BMC Public Health 15:583. https://doi.org/10.1186/s12889-015-1940-x

9. Brunstein Klomek A, Snir A, Apter A et al (2016) Association between victimization by bullying and direct self injurious behavior among adolescence in Europe: a ten-country study. Eur Child Adolesc Psychiatry 25:1183-1193. https://doi.org/10.1007/s0078 7-016-0840-7

10. Barzilay S, Brunstein Klomek A, Apter A et al (2017) Bullying victimization and suicide ideation and behavior among adolescents in Europe: a 10-country study. J Adolesc Health Off Publ Soc Adolesc Med 61:179-186. https://doi.org/10.1016/j.jadoh ealth.2017.02.002

11. Bond L, Carlin JB, Thomas L et al (2001) Does bullying cause emotional problems? A prospective study of young teenagers. BMJ 323:480-484. https://doi.org/10.1136/bmj.323.7311.480

12. Antila H, Arola R, Hakko $\mathrm{H}$ et al (2017) Bullying involvement in relation to personality disorders: a prospective follow-up of 508 inpatient adolescents. Eur Child Adolesc Psychiatry 26:779-789. https://doi.org/10.1007/s00787-017-0946-6

13. Wolke D, Lereya ST (2015) Long-term effects of bullying. Arch Dis Child 100:879-885. https://doi.org/10.1136/archdischi ld-2014-306667

14. Lereya ST, Copeland WE, Zammit S, Wolke D (2015) Bully/victims: a longitudinal, population-based cohort study of their mental health. Eur Child Adolesc Psychiatry 24:1461-1471. https://doi. org/10.1007/s00787-015-0705-5

15. Lereya ST, Copeland WE, Costello EJ, Wolke D (2015) Adult mental health consequences of peer bullying and maltreatment in childhood: two cohorts in two countries. Lancet Psychiatry 2:524-531. https://doi.org/10.1016/S2215-0366(15)00165-0

16. Mynard H, Joseph S, Alexander J (2000) Peer-victimisation and posttraumatic stress in adolescents. Personal Individ Differ 29:815-821. https://doi.org/10.1016/S0191-8869(99)00234-2

17. Idsoe T, Dyregrov A, Idsoe EC (2012) Bullying and PTSD symptoms. J Abnorm Child Psychol 40:901-911. https://doi. org/10.1007/s10802-012-9620-0

18. Leenarts LEW, Diehle J, Doreleijers TAH et al (2013) Evidencebased treatments for children with trauma-related psychopathology as a result of childhood maltreatment: a systematic review. Eur Child Adolesc Psychiatry 22:269-283. https://doi. org/10.1007/s00787-012-0367-5

19. Ttofi MM, Farrington DP (2011) Effectiveness of school-based programs to reduce bullying: a systematic and meta-analytic review. J Exp Criminol 7:27-56. https://doi.org/10.1007/s1129 2-010-9109-1

20. Becker SP, Mehari KR, Langberg JM, Evans SW (2017) Rates of peer victimization in young adolescents with ADHD and associations with internalizing symptoms and self-esteem. Eur Child Adolesc Psychiatry 26:201-214. https://doi.org/10.1007/s0078 7-016-0881-y

21. Thielen FW, Ten Have M, de Graaf R et al (2016) Long-term economic consequences of child maltreatment: a population-based study. Eur Child Adolesc Psychiatry 25:1297-1305. https://doi. org/10.1007/s00787-016-0850-5 